\title{
Educação em nível secundário de moças de Natal e de Coimbra (1941-1948)
}

\author{
Education at the secondary level of girls from \\ Natal and Coimbra (1941-1948) \\ Educación a nivel secundario de las jóvenes de \\ Natal y de Coimbra (1941-1948)
}

\author{
Marta Maria de AraúJo ${ }^{1}$; Cristina Maria CoImbra VIEIRA ${ }^{2}$
}

\section{Resumo}

No ano de 1941, as jovens Petronila da Silva Neri e Maria Isabel Dinis Pedroso de Lima Gonçalves Neves ingressaram no curso secundário do Ateneu Norte Riograndense (NatalBrasil) e no ensino liceal do Liceu Nacional Infanta D. Maria (Coimbra-Portugal). O trabalho, no que concerne à análise do corpus documental, fundamentou-se no entendimento de formação escolar e de autoformação feminina, de Pierré Dominicé (2014), com o objetivo de refletir sobre as dimensões formativas e autoformativas dessas jovens nos correspondentes cursos secundário e liceal, de 1941 a 1948. Em termos de conclusão, a análise histórica a que se procedeu revela que a formação escolar completa e uniforme e igualmente a autoformação das estudantes Petronila da Silva Neri e Maria Isabel Neves foram análogas às interações intergeracionais e às interações intrageracionais, planificadas por legislação especifica, normatizações e programa de estudo em razão de propósitos formativos universalizáveis e em face de uma "unidade geracional" dessa juventude estudantil.

Palavras-chave: Educação de mulheres. Ateneu Norte Riograndense. Liceu Nacional Infanta D. Maria.

1 Doutora em Educação pela Universidade de São Paulo. Professora Titular do Departamento de Fundamentos e Políticas da Educação do Centro de Educação da Universidade Federal do Rio Grande do Norte (Brasil). Líder do Grupo de Pesquisa "Estudos Históricos Educacionais" (UFRN/CNPq) e pesquisadora do "Grupo Interdisciplinar de Pesquisa, Formação (Auto)Biografia e Representações (GRIFAR/UFRN)". E-mail: martaujo@uol.com.br

${ }^{2}$ Doutora em Ciências da Educação (Psicologia da Educação) pela Universidade de Coimbra. Professora Associada na Faculdade de Psicologia e de Ciências da Educação da Universidade de Coimbra (Portugal). Investigadora do Centro de Estudos Interdisciplinares do Século XX (CEIS 20). Vice-Presidente da Sociedade Portuguesa de Ciências da Educação (SPCE) e Vice-Presidente da Associação Portuguesa de Estudos sobre as Mulheres (APEM).E-mail: vieira@fpce.uc.pt 


\begin{abstract}
In the year 1941, the youngsters Petronila da Silva Neri and Maria Isabel Dinis Pedroso de Lima Gonçalves Neves enrolled in the secondary course of the Ateneu Norte Riograndense (Natal-Brazil) and in the correspondent secondary level school of the Liceu Nacional Infanta D. Maria (Coimbra-Portugal). The work, with regard to the analysis of the documentary corpus, was based on Pierré Dominicé's understanding of school education and female self-tuition, with the purpose of reflecting on the formative and self-formative dimensions of these young women in the corresponding secondary degrees, from 1941 to 1948. In terms of conclusion, the historical analysis carried out reveals that the complete and uniform school formation and the self-tuition of the students Petronila da Silva Neri and Maria Isabel Neves were analogous to the intergenerational interactions and intragenerational interactions, planned by specific legislation, set of norms and study programs due to universalized formative purposes and in the face of a "generational unit" of this student youth.
\end{abstract}

Keywords: Education of women. Ateneu Norte Riograndense. Liceu Nacional Infanta D. Maria.

\title{
Resumen
}

En el año 1941, las jóvenes Petronila da Silva Neri y Maria Isabel Dinis Pedroso de Lima Gonçalves Neves ingresaron en el curso secundario del Ateneo Norte Riograndense (NatalBrasil) y en la enseñanza liceano del Liceo Nacional Infanta D. Maria (Coimbra-Portugal). El trabajo, en lo que concierne al análisis del corpus documental, se fundamentó en el entendimiento de formación escolar y de autoformación femenina, de Pierré Dominicé (2014), con el objetivo de reflexionar sobre las dimensiones formativas y auto formativas de esas jóvenes en los correspondientes cursos secundarios y liceano, de 1941 a 1948. En términos de conclusión, el análisis histórico a que se ha procedido revela que la formación escolar completa y uniforme y igualmente la autoformación de las estudiantes Petronila da Silva Neri y Maria Isabel Neves fueron análogas a las interacciones intergeneracionales y a las interacciones intrageneracionales, planificadas por legislación específica, normalizaciones y programa de estudio en razón de propósitos formativos universalizables y frente a una "unidad generacional" de esa juventud estudiantil.

Palabras clave: Educación de las mujeres. Ateneo Norte Riograndense. Liceo Nacional Infanta D. María. 


\section{Introdução}

Nos anos que antecederam, sucederam e mesmo no decursoda Segunda Guerra Mundial (1939-1945), o Bureau Internacional de Educação (BIE), posteriormente Bureau Internacional de Educação, e aOrganização das Nações Unidas para a Educação, a Ciência e a Cultura (Unesco) promoveram, na cidade de Genebra (Suíça) -1934 a 1939 e 1946 a 1963 -, as Conferências Internacionais de Instrução Pública.

A $1^{\text {a }}$ Conferência Internacional de Instrução Pública (1934, p. 3), a Recomendação $\mathrm{n}^{\circ} 2$-Admissão às Escolas Secundárias- propôsa igualdade de acesso ao ensino médio, além de uma maior "[...] coordenação entre o ensino primário e oensino secundário de maneira a permitir - sobretudo durante os primeiros anos de estudos - passagem facilitada de uma categoria de ensino a outra".

A $2^{\text {a }}$ Conferência Internacional de Instrução Pública (1935, p. 7), a Recomendação $n^{\circ} 5$ - Formação Profissional do Magistério Secundário- assinalou as reformas do ensino secundário, em desenvolvimento na maioria das nações partícipes dessas Conferências, vislumbrando, nesse processo, a oportunidade para melhorar o trabalho profissional e pedagógico dos professores desse nível de ensino, necessariamenteaquelesresponsáveis pela formação das elites nacionais. Nesse sentido, a Conferência clamava às autoridades educacionais nacionais uma formação científica dos professores secundários “[...] bastante desenvolvida, ministrada em instituições universitárias ou em estabelecimentos de ensinosuperior; por conseguinte, essa formação científica [comportava]obrigatoriamente a especialização".

Nessas Conferências Internacionais de Instrução Pública, as recomendações aprovadas, que se constituíam numconjunto de proposições para ser implementadas de conformidade com as particularidades educacionais das quase 100(cem) nações partícipes, estariam fundamentadas, por um lado, em princípios liberais universais de igualdade de oportunidades da educação pré-escolar, primária, secundária e universitária sem distinção de sexo, raça ou condição econômico-social; por outro lado, na proposição da interdependência crescente entre países com fins de harmonizar uma consciência global de cidadania.

Antes de tudo, tratava-sede proposições de fundamentos democráticos intrinsecamente relacionadas com a dimensão formativa da juventude, por intermédio da instituição escolar,querequeriam das nações partícipes decisões político-institucionais atinentes a uma unidade de igualdade de oportunidades escolares entre homens e mulheres, entre classes sociais, entre centros e periferias. Por conseguinte, aeducação em nível secundário elevava-se como uma das garantias da pacificação e do entendimento internacional de igualdade na formação dehomens e de mulheres. Era mais ou menos o que defendia Norberto Bobbio (2010, p. 39): “A igualdade não é um fato a ser constatado, mas um dever a ser realizado."

O trabalho, no que se refere à analise docorpus documental(entrevistas, legislação educacional, principalmente), fundamentou-se no entendimento de formação escolar e de autoformação feminina, sob a ótica de Pierré Dominicé (2014), com o objetivo de refletir sobre as dimensões formativas e autoformativas da jovem Petronila da Silva Neri no curso secundário ginasial do Ateneu Norte Riograndense e no Colégio 
Estadual do Rio Grande do Norte, situado em Natal (1941-1946) e da jovem Maria Isabel Dinis Pedroso de Lima Gonçalves Neves no ensino liceal ou secundário do Liceu Nacional Infanta D. Maria, situado em Coimbra (1941-1948), mediante as interações intergeracionais e intrageracionais.

\section{A educação formativa e autoformativa da jovem Petronila da Silva Neri}

No dia 31 de maio de 1926, nasceu, na cidade de Santa Cruz (Rio Grande do Norte), Petronila da Silva Neri, a vigésima filha (entre dezenove irmãos, sendo oito mulheres e onze homens), de Heleno Francisco da Silva (construtor de obras) e de Maria Vicência da Silva (responsável pelos afazeres domésticos e incumbida de educar os filhos).

No ano de 1936, com dez anos de idade, a menina Petronila (de condição social pobre e de religião protestante) foi matriculada pelos pais, para cursar da $2^{\mathrm{a}}$ à 5 série da educação primária, no Grupo Escolar "João Tibúrcio", da cidade de Natal (atualmente Escola Estadual Professor "João Tibúrcio"), localizado no bairro popular do Alecrim lugar onde residia a sua família.

No ano de 1940, a jovem Petronila foi aluna do curso preparatório para o Exame de Admissão, do austero Prof. Batalha, querevisava todas as matérias de estudos da $5^{\text {a }}$ série da educação primária. Segundo a senhora Petronila (2017), no Curso Preparatório do Prof. Batalha, para o Exame de Admissão, havia uma predominância de jovens do sexo feminino.

No ano seguinte (1941), a jovem Petronila foi aprovada no Exame de Admissão do Ateneu Norte Riograndense Feminino, para o curso secundário ginasial (primeiro ciclo, compreendendo quatro anos), prosseguindo, então, para o segundo ciclo do curso secundário - o cientifico (três anos de duração) -, devido à sua pretensão de estudar medicina em Recife (Pernambuco).

Nesse ano (1941), o Ateneu Norte Riograndense, ginásio oficial do Estado, era regido pelo Regimento Interno de 1933 (aprovado pelo Decreto $\mathrm{n}^{\circ}$ 160, de 30 de maio de 1933), de conformidade com o Decreto $\mathrm{n}^{\circ}$ 19.890, de 18 de abril de 1931, para ministrarunicamente o ensino secundário de Ciências e Letras (com a duração de cinco anos), de acordo com o Colégio Pedro II, da Capital Federal (Rio de Janeiro). As alunas e os alunos ginasianoseram sujeitos de aprendizado dos conhecimentosmais ou menos distintos das Ciências e das Letras, além de receberem uma sólida orientação educativa (atitudes, gestos, hábitos, linguagens, disciplina,obediência, respeito, responsabilidade, urbanidade, bem vestir e bem cuidar dos materiais escolares), visando a uma formação escolar completa e uniforme, que se entendia ser deveras necessária para os futurosidealizadores e condutores da nação brasileira.

No ano de 1943, com a promulgação da Lei Orgânica do Ensino Secundário em 1942 (aprovada pelo Decreto-Lei $n^{\circ}$ 4.244, de 9 de abril de 1942), o Ateneu Norte Riograndense denominar-se-ia Colégio Estadual do Rio Grande do Norte (Decreto $\mathrm{n}^{\circ}$ 1.166, de 10 de março de 1943), com dois ciclos do curso secundário: o1 ${ }^{\circ}$ ciclo ginasial (com quatro anos) e o $2^{\circ}$ ciclo científico e clássico (com três anos). Ocurso secundário nociclo ginasial, para as alunas, seria ministrado em classesexclusivamente femininas. 
Aos professores do Ateneu Norte Riograndense - posteriormente Colégio Estadual do Rio Grande do Norte - competia ensinaros conhecimentos escolares constitutivos das Ciências e das Letras, por intermédio das matérias do programa de estudo para o conjunto dosestudantes de cada classe escolar, com o evidente propósito de uma formação escolar completa e uniforme (mental, intelectual, moral, física) que transcendesse para uma autoformação igualmente completa e uniforme.

Essa formação escolar completa e uniforme da juventude, no curso secundário no Ateneu Norte Riograndense e no Colégio Estadual do Rio Grande do Norte, referenciavase, fundamentalmente, em concepções educacionais; formulações pedagógicas, normatizações,codificação dos conhecimentos intrínsecos às Ciências e às Letras e ainda na reforma educativa como continuidade da reforma antecedente e nas exigências sociais vigentes para, assim, formaratitudesde disciplina e responsabilidade, sentimentos humanos e valores morais e cívicos,capacidade de decisão e dededicação,ideais nacionais e internacionais, além de sublinhar a necessidade de empreender esforço para os estudos mais elevados da formação universitária especializada.

Aformação escolar completa e uniforme, especialmente das estudantes secundaristas, mediante as matérias do programa de estudo levado a efeito pelas professoras e professores da senhora Petronila, que foram análogas às interações intergeracionais (estudantes da mesma classe de idades aproximadas) e às interações intrageracionais (pais, filhos; professoras, professores, estudantes de idades aproximadas) deverá ser analisada pelas respostas da entrevista oral com ela realizada.

No período de 1941-1944, quando a jovem Petronila cursou o $1^{\circ}$ ciclo ginasial do nível de ensino secundário no Ateneu Norte Riograndense Feminino (que funcionava, à época, no Grupo Escolar Modelo "Dr. Antônio de Mello e Souza", hoje Fundação José Augusto), com mais ou menos quarenta colegas (todas fardadas com blusa branca e uma saia de cor verde com pregas e sapato de cor preta com meia branca), foram seus professores, por matéria do programa de estudo: Angélica Moura (Português e Latim); Etelvina Emerenciano (Francês); Ivone Barbalho (Inglês); Águeda Toscano (Matemática); Bertilde Guerra (Geografia); Monsenhor Landim (História da Civilização) e Cecília Oliveira(Educação Física e Música). Ao descrever sobre a sua formação escolar, compatível com o ciclo ginasial do curso secundário, a senhora Petronila assinalou seu capital cultural - para utilizar essa noção de Bourdieu (2011) - em seus elementos normativo, pedagógico e escolar conjuntamente, assim se pronunciando:

A prof. ${ }^{a}$ Angélica Moura (Português e Latim), mulher carismática e jovial, estava sempre preocupada em desenvolver, nos seus alunos, valores acadêmicos, morais e éticos.

$[\ldots]$

A prof. ${ }^{a}$ Etelvina Emerenciano (Francês) - naquela época - ela já dizia que não estava preocupada, apenas, com o ensino de língua francesa. Para ela, o mais importante era a formação da conduta íntegra do ser humano. Em todas as suas aulas, invariavelmente, ela deixava uma lição de vida humana e social. 


\section{[...]}

A prof. ${ }^{a}$ Marieta Guerra (Francês) adotava uma metodologia idêntica à da prof. ${ }^{a}$ Etelvina Emerenciano: preocupava-se em oferecer uma formação completa às alunas, que demonstravam muito interesse pelas suas aulas.

$[\ldots]$

A prof. ${ }^{\text {a }}$ Águeda Toscano (Matemática), que mantinha um bom relacionamento com a nossa turma, procurava ensinar a disciplina de maneira bem descontraída, ou seja, com exemplos vivenciados pelas alunas no seu dia a dia. Mesmo assim, as alunas não se sentiam muito à vontade para fazer perguntas e tirar dúvidas (NERI, 2017, p. 3-4).

Concluindoa descrição de sua formação escolar do $1^{\circ}$ ciclo ginasial do curso secundário, a Senhora Petronila Silva cita um único professor: o Monsenhor João da Mata Paiva(Diretor do Ateneu Norte Riograndense), conforme sua recordação:

Ele foi um diretor que deixou referências indeléveis em minha formação humana. Conhecia todos as alunas pelo nome; inclusive, sempre que o tempo permitia, costumava visitá-las em suas casas. Foi um grande incentivador das atividades culturais do Grêmio Escolar "Auta de Souza”(NERI, 2017, p. 4-5).

No período de 1945 e 1946, quando a jovem Petronila estudou, por dois anos, o2 ${ }^{\circ}$ ciclo científico do curso secundáriono Colégio Estadual do Rio Grande do Norte (prédio construído no início do século XX, localizado na rua Junqueira Aires), com mais ou menos quarenta colegas mulheres e homens,foram seus professores, por matéria do programa de estudo: Edgard Barbosa (Português); Esmeraldino Siqueira (Francês); Monsenhor Landim (Latim); Protásio Melo (Inglês e Ciência); José Gurgel (Física); Cônego Luís Wanderley (Matemática);Sebastião Monte (Biologia); Lourdes Guilherme; (História Geral); Clementino Câmara (História do Brasil); Rômulo Wanderley (Geografia) e Cecília Oliveira (Educação Física e Música). No relato da sua formação escolar, compatível com o $2^{\circ}$ ciclo científico do curso secundário, a senhora Petronila, igualmente, especificou aquele capital cultural, em seus elementos normativo, pedagógico e escolar conjuntamente:

Ao prof. Edgard Barbosa (Português), devo a minha paixão pela leitura que, ainda hoje, perdura. Ele primava pela elegância da língua portuguesa e me indicava, e emprestava, livros para eu ler.

$[\ldots]$

O prof. Esmeraldo Siqueira (Francês) ficou na minha lembrança pela sua reconhecida inteligência e domínio profundo da língua francesa.

$[\ldots]$

O prof. Protásio Melo(Inglês e Ciências) - sempre elegante na maneira de ser e de vestir-se - era detentor de uma voz que inspirava muita autoridade. Mas, na essência, era um professor comprometido com a aprendizagem de todos os seus alunos (NERI, 2017, p. 10). 
Em razão da dimensão prospectiva de umaformação completa e uniforme dos estudantes do $2^{\circ}$ ciclo do científico e clássico do curso secundário, as atividades culturais do Grêmio Escolar "Auta de Souza" (peças de teatro, danças, poesias, excursões) - tinham os professores Protásio Melo e Celestino Pimentel (diretor do Colégio Estadual do Rio Grande do Norte) como os seus mais reconhecidos incentivadores.

Evidente que, para a senhora Petronila, as suas professaras e os seus professores do $1^{\circ}$ ciclo e do $2^{\circ}$ ciclo do ginasial e científico do curso secundário entendiam que a sua missão consistia,principalmente, em transmitir os conhecimentos das matérias de estudo num exercício de competência, seriedade e rigor para formar os seus alunospara avida adulta ou, como assinala Teixeira (2001, p. 98), “[...] para o seu tempo de chegada à vida social”. Embora obedecesse ao estabelecido, a senhora Petronila (2017, p. 10) demostra sua reação-resposta:"Muitas vezes eu sentia vontade de divergir de um professor ou professora. Quem se atrevia a isso? Seria ir de encontro às regras acadêmicas de respeito aos professores da Instituição".

Como a educação formativa continha, em seus propósitos, uma formação escolar completa e uniforme, que transcendesse para uma autoformação igualmente completa e uniforme, pedimos à senhora Pentronila que descrevesse os seus esforços para alcançar sua autoformação, tendo em vista as demandas da formação escolar nos $1^{\circ}$ e $2^{\circ}$ ciclos ginasial e científico do curso secundário. Sua descrição é esclarecedora:

Eu estudava todos os dias, preferencialmente no horário da madrugada, no quintal da minha casa. Estudava para as arguições em sala de aula (perguntas e respostas dos conteúdos das matérias curriculares) e para as provas, lendo nos livros e nos cadernos.

[...]

Os meus pais compravam todos os livros adotados pelos professores do Ateneu para a minha formação. Diariamente, sentávamos à mesa para que acompanhassem os nossos trabalhos da escola para casa.

$[\ldots]$

Uma matéria que considerava difícil era matemática. Para ser bemsucedida nas arguições e nas provas de matemática, os meus pais pagavam ao prof. Baltazar para me dar aula particular de matemática na casa dele.

[...]

História do Brasil foi outra matéria cujo conteúdo eu apresentava dificuldades. Por isso, os meus pais resolveram contratar o prof. Clementino Câmara para ministrar aulas de reforço na casa dele para que eu melhorasse nos estudos de História do Brasil (NERI, 2017, p. 9).

E para sintetizar, a senhora Petronila (2017, p. 9 e 10), assim arremata:"Era visível e louvável o empenho dos meus pais, não obstante com pouco estudo, para que nos tornássemos pessoas bem formadas e letradas, já que eles não tiveram essa mesma oportunidade".

Antes de concluir o segundo ano do $2^{\circ}$ ciclo científico secundário, a senhora Petronila casou-se com o senhor Melquíades Felipe Neri, que apenas havia cursado a educação primária (incompleta) e trabalhava num bar, vindo, posteriormente, a trabalhar 
no Serviço de Combate às Epidemias Rurais. A senhora Petronila foi a principal educadora dos três filhos: Vilma Silva Neri (formada em Letras e Pedagogia), Magda Silva Neri (formada em Letras e Pedagogia) e Gilberto Silva Neri (formado em Ciências Sociais).

\section{A educação formativa e autoformativa da jovem Maria Isabel Dinis Pedroso de Lima Gonçalves Neves}

Em uma família de tradição católica, residente numa sub-região do Pinhal Interior,norte de Portugal,ainda hoje com fortes traços de ruralidade, nasceu, no dia 2 de julho de 1931, uma menina que viria a se tornar uma das moças de maior destaque na educação formal e na vida cívica e políticadas gerações seguintes de Vila Nova de Poiares. Maria Isabel Dinis Pedroso de Lima Gonçalves Neves é a filha mais nova de uma prole de sete crianças (5 do sexo masculino e 2 do sexo feminino), nascidas do casal Mário Júlio de Ferreira Lima e Adélia Vieira Dinis de Ferreira Lima. Os pais tinham completado o curso primário: a mãe era doméstica e se dedicava sobretudo ao cuidado da sua extensa família; o pai exercia a profissão de ajudante de Farmácia.

A família de D. Isabelinha, como ainda hoje é carinhosamente tratada por todos quantos privam de sua íntima convivência, encarava a educação como um valor útil para a vida em sociedade; e por isso se empenhou na educação de seus filhos: todos eles completaram a escolaridade obrigatória à época, e depois concluíram o ensino liceal ou secundário. Os quatro anos do ensino primário foram cursados na escola sede do Concelho de Vila Nova de Poiares. A necessidade de cursar o liceu obrigou a família a mudar-se para Coimbra, cidade que distava cerca de 35 quilômetros da área inicial de sua residência.

Em 1940 (ano em que concluiu a educação primária), D. Isabelinha prestou o exame de Admissão no Colégio Progresso. Aprovada, estudou, de 1941 a 1943, parte do $1^{\circ}$ ciclo ( $1^{\circ}$ e $2^{\circ}$ anos) do ensino liceal ou secundário nessa instituição. Em 1943, o seu pai resolveu matriculá-la no Liceu Nacional Infanta D. Maria, onde estudou, de 1943 a 1948, a outra parte do $1^{\circ}$ ciclo, e o $2^{\circ}$ e $3^{\circ}$ ciclos $\left(2^{\circ}\right.$ ao $7^{\circ}$ ano do ensino liceal ou secundário), período que coincidiu com a presidência de António de Oliveira Salazar no Conselho de Ministros (1933-1968), conforme Araújo, Alcoforado e Ferreira (2015, p. 28), caracterizado "[...] como um regime de ditadura unipessoal, de caráter nacionalista e corporativista [...]". Depois da "Revolução dos Cravos" (abril de 1974), e com o subsequente estabelecimento do regime democrático em Portugal, o Liceu, que até àquela altura somente admitia estudantes do sexo feminino, passou a ser misto (1975), mudando sua designação para Escola Secundária Infanta D. Maria.

Inicialmente conhecido como Liceu Feminino de Coimbra, criado pelo Decreto ${ }^{\circ}$ 4.650, de 14 de julho de 1918, foi designado, no ano seguinte de 1919, Liceu Nacional Infanta D. Maria. As alunas secundaristas eram estudantes de aprendizado de conhecimentos da cultura geral para os estudos superiores, além de receberem educação destinada ao desenvolvimento não apenas do intelecto mas também dos sentidos humanos, da saúde física, do caráter e da valorização do lar e da família.

Por sua vez, o ensino liceal segregado por sexos obrigou D. Isabelinha a frequentar esta instituição (Liceu Nacional Infanta D. Maria), que era exclusiva para o sexo feminino e que tinha no seu corpo docente apenas professoras, sendo, inclusive, 
dirigido por uma Reitora: Dionísia Camões de Mendonça. A instituição equivalente para o sexo masculino era o Liceu D. João III, que ficava situado em local diferente da cidade. A entrevista feita com D. Isabelinha incidiu especialmente sobre a sua formação escolar e sua autoformação.

A formação escolar completa e uniforme, em nível liceal, de D. Isabelinha, em particular no Liceu Nacional Infanta D. Maria (1943-1948), nos termos do Decreto-Lei ${ }^{\circ}$ 27.084, de 14 de outubro de 1936 (que regulamentava o ensino liceal ou secundário à época), compreendeu um programa de estudo estruturado emtrês ciclos sucessivos, com a devida correlação dos conhecimentos ensinados: $1^{\circ}$ ciclo $\left(1^{\circ}, 2^{\circ}\right.$ e $3^{\circ}$ anos $) ; 2^{\circ}$ ciclo $\left(4^{\circ}, 5^{\circ}\right.$ e $6^{\circ}$ anos); e $3^{\circ}$ ciclo ( $7^{\circ}$ ano). Abrangia 19 matérias, quais sejam: Português ( $1^{\circ}$ ciclo); Francês ( $1^{\circ}$ ciclo); Ciências Geográfico-Naturais $\left(1^{\circ}\right.$ e $2^{\circ}$ ciclos $)$; Matemática $\left(1^{\circ}, 2^{\circ}\right.$ e $3^{\circ}$ ciclos); Desenhoe Trabalhos Manuais ( $1^{\circ}$ ciclo); Português-Latim ( $2^{\circ}$ ciclo); Alemão ou Inglês ( $2^{\circ}$ ciclo); História ( $2^{\circ}$ ciclo); Língua e Literatura Portuguesa ( $3^{\circ}$ ciclo); Latim ( $3^{\circ}$ ciclo); Ciências Geográficas ( $3^{\circ}$ ciclo); Ciências Biológicas ( $3^{\circ}$ ciclo); Ciências FísicoQuímicas ( $3^{\circ}$ ciclo); Organização Política e Administrativa da Nação ( $3^{\circ}$ ciclo) eFilosofia ( $3^{\circ}$ ciclo).Além das Sessões de Educação Moral e Cívica ( $1^{\circ}$ e $2^{\circ}$ ciclos), Educação Física $\left(1^{\circ}, 2^{\circ}\right.$ e $3^{\circ}$ ciclos $)$, Canto Coral $\left(1^{\circ}, 2^{\circ}\right.$ e $3^{\circ}$ ciclos $)$, Higiene $\left(2^{\circ}\right.$ e $3^{\circ}$ ciclos $)$ e Educação Familiar ( $3^{\circ}$ ciclo).

A respeito de sua formação escolar em nível liceal, D. Isabelinha recordou ainda da matéria Educação Feminina. Afinal, se se pretendiaeducar a juventude para dotá-la de uma formação completa e uniforme, útil para a vida na sociedade portuguesa era, então, para as autoridades portuguesas (Decreto-Lei $\mathrm{n}^{\circ}$ 27.084, de 14 de outubro de 1936, p. 1236), indispensável integrar o ensino liceal "[...] na missão educativa da Família e do Estado [...], igualmente na devoção para com a Pátria, nosentimento de ordem, no gosto da disciplina [...]" e na modelação da vontade.

Para concretizar essa formação escolar completa e uniforme da juventude portuguesa, as interações intrageracionais deveriam cercar-se da verticalidade do respeito, do rigor acadêmico,da ordem, da disciplina,dimensões que D. Isabelinha considera terem sido fundamentais para a sua formação e a sua autoformação. De fato, no enlace entre as interações intrageracionais (professoras e alunas) e as interações intergeracionais(alunas do curso secundário) prevaleceu uma austera formação feminina, como relata D. Isabelinha:

A professora em cima do estrado e nós a ouvir. A Reitora era muito exigente. Havia, de vez em quando, uma expulsão da aula, ou por conversas entre alunas, ou por uma indelicadeza para com a professora [...], mas eram situações raras.

$[\ldots]$

As aulas eram rígidas, com a duração de 45 minutos;os intervalos eram bastante vigiados e nós a única coisa que fazíamos era andar ali de um lado para o outro, durante 10 minutos, a falar umas com as outras. Tocava a campainha e entravámos na sala.

$[\ldots]$

Chegávamos ao ponto de não podermos andar de braço dado nos recreios, devido ao rigor imposto pela Reitora [...] (NEVES, 2017, p. 2). 
Entre os materiaisescolares exigidos para as atividades pedagógicas e indispensáveis para uma formação escolar,estavam os livros e os cadernos diários, sempre em ordem e obrigatórios, o que era próprio do Liceu, além de tinta, aquarelas, guaches etc. Evidentemente, a formação escolar das alunasincluía o método de ensino cumprido pelas professoras, conforme revela D. Isabelinha:

Havia ensino expositivo, disciplina rígida e pouco material didático. As salas tinham quadro preto e globo. As carteiras eram de madeira, de formato próprio, sendo apenas algumas de dois lugares. Não havia símbolos religiosos.

$[\ldots]$

Quanto ao material didático trazido pelas professoras, só me lembro de uma professora de matemática que trouxe uns ferrinhos com cores para nos ajudar a aprender a matéria(NEVES, 2017, p. 3 e 4).

A vida escolar noLiceu Nacional Infanta D. Maria (1943-1948), com cerca de 30 alunas por classe de aula nos dois primeiros ciclos, estendia-se ao emprego de algumas simbologias, como o lema de cada turma em latim. O lema da turma de D. Isabelinha era: "Trabalho Vence Tudo" (Labor Improbus Omnia Vincit).

No rigor do cumprimento das interações intrageracionais e das interações intergeracionais, as professoras usavam uma bata branca. Às alunas eram destinadas batas de sete cores diferentes, sendo que pelo menos uma cor acompanhava os ciclos escolares. A aluna quechumbasse (que fosse reprovada)seria imediatamente identificada, por ter uma cor diferente de bata do restante do grupo de colegas. Orelato de D. Isabelinha elucida diferenças e obrigatoriedades do sistema educativo português da sua época de estudante secundarista:

No Liceu, era obrigatória a bata; cada ano, cada cor; levava-se falta injustificada caso não se levasse a farda. Também não era permitido andar sem meias. Mesmo que andássemos de sandálias, usávamos também meias. As calças eram proibidas.

$[\ldots]$

Havia sete cores: bege, cor-de-rosa, salmão, verde, azul, amarelo, roxo. A professora tinha bata branca. Cada cor distinguia o ano das alunas e só mudava o tamanho. A bata tinha um modelo próprio: elástico na cinta, cabeção,bolsos, abotoava atrás e era prática.

[...]

A farda da ginástica era um calção azul claro, de algodão, igual para toda a gente, com elástico até abaixo do joelho, e com uma saia por cima. A parte de cima era uma t-shirt normal, também de cor azul. Esta farda era própria para todo o tipo de exercícios. Quando usávamos o espaldar, era um escândalo se mostrássemos as pernas. O calção com o elástico era mais apropriado.

$[\ldots]$

No ano em que eu entrei, a cor da bata era a verde e nós víamos as finalistas, 'as senhoras', com uma bata azul (NEVES, 2017, p. 4). 
Por conseguinte, a formação escolar das alunasera permeada por algumas atividades de sociabilidades extraclasses; também autoformativas, embora a instituição escolar não estivesse aberta à comunidade.Com a finalidade de educar, instruir e formar a juventude pelos padrões da história oficial pátria e pelos valores de civismo e de coesão social dominantes, as professoras planejavam visitas de estudo e excursões aos monumentos emuseus da cidade, além de promoverem sessões culturais (palestras feitas por médicos, professores, dentre outros profissionais).

As interações intrageracionais da família com as professoras do Liceu Nacional Infanta D. Mariainterpunham-se quando da assinatura das folhas de exames das alunas e quando a diretora de turma recebia os pais, até em vista de uma unidade moral entre escola e família.Nas palavras deD. Isabelinha (2017, p. 5), funcionava da seguinte forma: "Nós levamos os pontos para os pais assinarem e pronto! Não havia sistematicidade das reuniões das professoras com as famílias [...]. Pouco havia contato entre as famílias e a vida escolar".

Numa análise mais acurada dessas dimensões formativas e autoformativas de D. Isabelinha no ensino liceal ou secundário, particularmente no que concerne às interações intergeracionais e intrageracionais, atenta-se para o fato de não haver, no Liceu, uma Associação de Estudantes. Mas havia uma Organização Nacional denominada Mocidade Portuguesa, que ministrava aulas de "Educação Feminina", para ensinar tudo o que, em última instância, instruísse as alunas em proveito de um ordenamento da vida do lar e da vida social que as circundava. D. Isabelinha relatou que, nas aulas de "Educação Feminina" da Mocidade Portuguesa, sempre ministradas na quarta-feira, no horário da tarde, os ensinamentos eram de lavores (trabalhos manuais), culinária, regras de etiqueta, valores religiosos etc.

A propósito de sua formação escolar no Liceu Nacional Infanta D. Maria (19431948), circundada pelas interações intrageracionais e pelas interações intergeracionais, D. Isabelinha considera que tudo o que muitoestudou e muitoaprendeu no Liceu foi de caráter positivo. Exercendo a sua profissão de professora, antes e depois da instauração do regime democrático em Portugal, ela admite que foi a sua formação escolar liceal que cultivou nela os esforços de autoformação para saber mais, para enfrentar a vida, fosse em tarefas da vida diária, fosse no domínio da cultura portuguesa:

Avalio a experiência como rígida, mas bastante positiva. Ainda hoje tenho uma grande admiração pela Reitora. A educação que recebemos no Liceu preparou-nos para a vida. Criou em nós a vontade de nos cultivarmos(NEVES, 2017, p. 5).

O manifesto de apreço pela dedicação do corpo docente ao ensino e, consequentemente, à sua formação escolar e autoformação foi reiterado por Isabel Maria Henriques Pedro (2010, p. 3), que fez uma tese de Mestrado sobre a educação liceal ou secundária das jovens que frequentaram o Liceu Infanta D. Maria, na qual faz a seguinte revelação: "As Professoras, conscientes do seu papel enquanto transmissoras de conhecimentos e devalores, orientadas pela reitora, tudo faziam dentro e fora da sala de aula para que as alunasterminassem cada ano com sucesso.” 
Aliás, D. Isabelinha tinha planos de seguir seus estudos superiores na área de História e Filosofia. E até frequentou mais um ano (opcional) após o ensino liceal ou secundário; mas o pai não lhe fez a vontade de apoiá-la nessa decisão de ir para a Universidade e ela desistiu. Entre 1950 e 1952, frequentou a Escola do Magistério Primário, tornando-se professora primária, profissão que exerceu durante cerca de quarenta anos, até se aposentar.

\section{Conclusão}

O historiador da educação Julia (2001) chama a atenção para as transferências culturais dirigidas às instituições educacionais, referentes aos conhecimentos e às formas de ensinar.Um exemplo disso são as Recomendações da $1^{\text {a }}$ Conferência Internacional de Instrução Pública (1934) e da $2^{a}$ Conferência Internacional de Instrução Pública (1935) quanto àadmissão, pelas escolas secundárias, de uma igualdade de acesso para homens e mulheres equanto à prioridade daformação profissional do magistério secundário, como meio de garantir a formação das elites nacionais. No entanto, as observâncias das Recomendações dessas Conferências Internacionais de Instrução Pública dependiam da correlação entre variáveis educacionais, econômicas, ideológicas, morais sociais e políticas de cada nação.

É no domínio da socialização dos conhecimentos das Ciências e das Letras na sua generalidade, repartidos no programa de estudo do curso secundário ginasial $\left(1^{\circ}\right.$ ciclo $)$ e do curso científico ( $2^{\circ}$ ciclo) do Ateneu Norte Riograndense e do Colégio Estadual do Rio Grande do Norte, da cidade de Natal, bem como do Colégio Progresso e do Liceu Infanta D. Maria, da cidade de Coimbra, do ensino liceal ou secundário $\left(1^{\circ} 2^{\circ}\right.$ e $3^{\circ}$ ciclos $)$, que se fazem perceber as matrizes das dimensões formativas da educação da senhora Petronila e de D. Isabelinha - a formação escolar dita completa e uniforme.De fato, como mostra Bourdieu (1997, p. 105), é precisamente por meio da formação escolar que o poder público,tanto reproduzo capital cultural dominante quanto"[...] molda as estruturas mentais e impõe os princípios de visão e divisão comuns, além de formas de pensar que estão para o pensamento culto [...]". A formação escolar da senhora Petronila e de D. Isabelinha tinha, em comum, os valoresmorais que presidem a própria estrutura da sociedade de cada país.

Nesse sentido, Bourdieu (1997, p. 88), destaca que a relevância do conhecimento constitutivo das ciências em geralpara a socialização da formação escolar do estudante é, indispensavelmente, parte integrante do universo social com suas noções e ideaisgeralmente dominantes "[...] de poder, de capital, de relação de forças, de lutas para conservar ou transformar essas relações de força, de estratégias de manutenção ou de subversão, de interesses etc". Como bem pondera Boto (2004), a reprodução social contida no ato de ensinar e de educar intergeraçõesteria sido presumida pelo sociólogo francês Émile Durkheim.

Para efeito da reprodução social e da própria preservação da coesão da estruturainstitucional, educacional, social, econômica, moral, política, ideológica das sociedades capitalistas, o sociológico Durkheim (1978, p. 45) confirmava: "É a ciência afinal que elabora as noções cardeais, que domina o pensamento: a noção de causa, de lei, de espaço, de número; noções de corpo, de vida, de consciência, de sociedade etc." Nesse 
sentido, integram-se aos conhecimentos das ciências em geral, socializados, os fins da educação com seus propósitos formativos por parte das instituições educativas como a escola e, por extensão, a família, que se transmite de geração em geração.

O educador e pesquisador Azanha (2002, p. 67), evidenciando o caráter institucional que medeia as interações intergeracionais e as interações intrageracionais, assinala a prevalência, no trabalho pedagógico dos professores em geral, "[...] de um fortecomponente de regulação social" [...], obviamente legitimado pela sociedade de que faz parte.

Conforme Dominicé (2014, p. 89), a formação (em geral) e a formação escolar (em particular) assemelham-se, portanto, a uma "[...] socialização "[...] nos contextos familiares, escolares e profissionais constituem lugares de regulação de processos específicos que se enredam uns nos outros, imprimindo uma forma original a cada história de vida". Por conseguinte, a autoformação, de modo especial a feminina, é comumente, para Pierré Dominicé (2014, p. 105), “[...] a luta de emancipação para a apropriação do poder de formação e para a construção de um mundo próprio, de espaços pessoais; [...] pelo estabelecimento de relações ativas de organização dos elementos que a rodeiam".

Em Natal (Rio Grande do Norte, Brasil) e em Coimbra (Portugal), a formação escolar completa e uniforme das mulheres no ensino secundário, perpassada pelo diálogo e pelos conflitos no plano global, nacional, regional e local, em razão do reconhecimento do estatuto dos saberes científicos, clássicos e empíricos, de naturezacosmopolita, haveria de ser universalizável nos seus propósitos formativos, tanto para as mulheres quanto para os homens em face das sociabilidades da vida profissional, concernentesao sistema capitalista, com suas resoluções necessariamente universalizantes.

No período de 1941 a 1948, a formação escolar mais ou menos completa e mais ou menos uniforme, como a autoformação das jovens Petronila da Silva Neri e Maria Isabel Dinis Pedroso de Lima Gonçalves Neves,no curso secundário do Atheneu Norte Rio-Grandense e noColégio Estadual do Rio Grande do Norte, da cidade de Natal, e no ensino liceal ou secundário do Liceu Infanta Dona Maria, da cidade de Coimbra, foram análogas às interações intergeracionais e às interações intrageracionais, por intermédio de uma socialização metódica dos conhecimentos constitutivos das ciências em geral, combinadas com os ciclos de estudos e os ciclos da idade, planificadas por legislação especifica, normatizações e programa de estudo, em razão dos propósitos formativos e em face de uma "unidade geracional"dessa juventude estudantil, tanto na nação brasileira quanto na nação portuguesa.

\section{Referências}

ARAÚJO, Marta Maria de; ALCOFORADO, Joaquim Luís Medeiros; FERREIRA, António Gomes. A educação supletiva nas Campanhas de Jovens e Adultos no Brasil e em Portugal (Século XX). Revista Educação em Questão, Natal, v. 53, n.39, p. 12-44, set./dez. 2015.

AZANHA, José Mário Pires. Cultura escolar brasileira. Um programa de pesquisa. Cadernos de História e Filosofia da Educação, São Paulo, v. 5, n. 7, p. 65-74, 2002. 
BRASIL. Decreto $n^{\circ} 19.890$, de 18 de abril de 1931. Dispõe sobre a organização do ensino secundário. Disponível em: http://www2.camara.leg.br/legin/fed/decret/19301939/decreto-19890-18-abril-1931-504631-publicacaooriginal-141245-pe.html. Acesso em: 13 maio 2017.

. Lei Orgânica do Ensino Secundário. Aprovada pelo Decreto-Lei n ${ }^{\circ} 4.244$, de 9 de abril de 1942. Disponível em: http://www.planalto.gov.br/ccivil_03/decreto-lei/19371946/Del4244.htm. Acesso em: 13 maio. 2017.

BOBBIO, Norberto. Qual democracia? Tradução Marcelo Perine. São Paulo: Edições Loyola, 2010.

BOTO, Carlota. Pedagogia: campo das ciências humanas às voltas da misteriosa arte de ensinar. Revista Educação em Questão, v. 21, n. 7, p. 37-68, set./dez. 2004.

BOURDIEU, Pierre. Razões práticas. Sobre a teoria da ação. Tradução Mariza Corrêa. Campinas: Papirus, 1997.

Capital cultural,escuela y espacio social. Tradução Isabel Jiminéz. México: Cidade do México, 2011.

CONFERÊNCIAS Internacionais de Instrução Pública. Recomendações (1934-1963). Brasília: Ministério da Educação e Cultura e Instituto Nacional de Estudos Pedagógicos, 1965.

DOMINICÉ, Pierre. O processo de formação e alguns dos seus componentes relacionais. In: NÓVOA, António; FINGER, Matthias (Org.). O método(auto) biográfico e a formação. Tradução Maria Nóvoa. 2. ed. Natal: EDUFRN, 2014.

DURKHEIM, Émile. Educação e sociologia. Tradução Lourenço Filho. 12. ed. São Paulo: Edições Melhoramentos, 1978.

JULIA, Dominique. A cultura escolar como objeto histórico. Revista Brasileira de História da Educação, São Paulo, n. 1, p. 9-43, jan./jun. 2001.

TEIXEIRA, Inês Assunção de Castro. Temporalidades com(viventes) nos territórios da educação. Educação em Revista, Belo Horizonte n. 34, p. 85-102, dez. 2001.

NERI, Petronila da Silva. A educação em nível secundário. Natal, 13, 19, 27 e 30 mar.

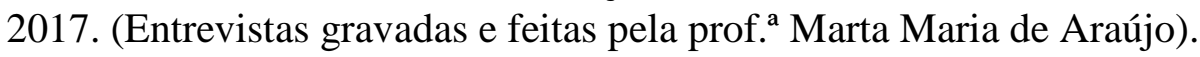

NEVES, Maria Isabel Dinis Pedroso de Lima Gonçalves. A educação em nível secundário. Coimbra, 29 e 31 ago. 2017 (Entrevistas gravadas e feitas pela prof. ${ }^{\text {a }}$ Dr. ${ }^{a}$ Cristina Maria Coimbra Vieira).

PEDRO, Maria Isabel Henriques. A mocidade portuguesa feminina no Liceu Nacional Infanta D. Maria de Coimbra: contributo para o estudo da educação em Portugal. Tese de Mestrado. 2010. Faculdade de Letras da Universidade de Coimbra, 2010.

RIO GRANDE DO NORTE. Regimento Interno do Ateneu Norte Rio-Grandense. Aprovado pelo Decreto ${ }^{\circ} 160$, de 30 de maio de 1933. Decretos do Governo (1933janeiro a junho). Natal: Imprensa Oficial, [1933]. 
RIO GRANDE DO NORTE. Decreto ${ }^{\circ} 1.166$, de 10 de março de 1943. Muda a denominação do Ateneu Norte Rio-Grandense para Colégio Estadual do Rio Grande do Norte. Diário Oficial [do] Estado. Poder Executivo, Natal, RN, 12 mar. 1943. p. 4 (A República).

PORTUGAL. Decreto $n^{\circ}$ 4650, de 14 de julho de 1918. Reforma os serviços da Instrução Secundária. Diário [da] República. Poder Executivo, Lisboa, Portugal, n. 157/18, 1918. p. 1313-1323 (Serie I, $2^{\circ}$ Suplemento). Disponível em: http://www.leideportugal.com/diarioprimeira-serie/1918-07-14/40. Acesso em: 30 ago. 2017.

Decreto-Lei $\mathrm{n}^{\circ} 27.084$, de 14 de outubro de 1936. Promulga a reforma do ensino liceal. Diário [do] Governo, Lisboa, 14 out. 1936. 